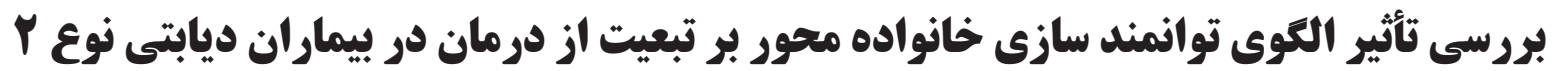

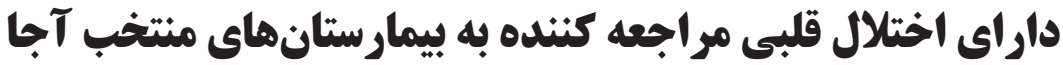

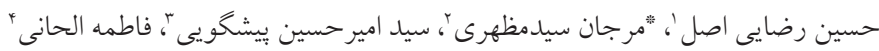

جكيده

مقدمه: آموزش در ديابت و اختلالات قلبى يك مسئله اساسى و مهرم در دستيابى به توانمندسازى و تبعيت مطلوب بيمار از رزيم درمانى است توجه به توانمندسازى خانواده بيماران نيز مىتواند مديريت و كنترل مطلوب بيمارى را در بيمار تسهيل نمايد. به همين منظور اين مطالعه با هدف تعيين تأثير بكارگيرى الگوى توانمندسازى خانواده محور بر تبعيت از درمان در بيماران مبتلا به ديابت نوع دو داراى اختلالات قلبى صورت پذيرفت.

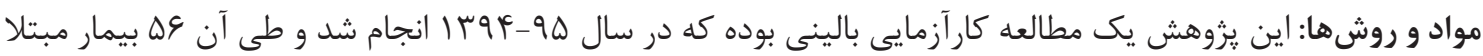
به ديابت نوع دو داراى اختلالات قلبى در بيمارستانهاى منتخب تابعه آجا بر اساس معيارهاى ورود، واحدهاى مورد يزوهش انتخاب و به صورت تصادفى به دو گروه مداخله و كنترل تقسيم و مورد بررسى قرار گرفت. براى گروه مداخله طى ᄉ جلسه • • تا • •و دقيقهاى بر طبق الكو آموزشهاى لازم داده شد و از آنان درخواست شد اين آموزشها را با خانواده خود در ميان بحذارند. ابزار جمعآورى دادهها يرسشنامههاى اطلاعات فردى، توانمندى و تبعيت از درمان در بيمارىهاى مزمن بود كه همه يرسشنامهها قبل از مداخله و يس از مداخله و يرسشنامه تبعيت از درمان مجددا جهار هفته يس از مداخله در اختيار دو گروه و خانواده آنان قرار زرفت. دادهها در نرمافزار SPSS نسخه آ با استفاده از آزمون دقيق فيشر، تى زوجى، تى مستقل و آناليز آنوا و آزمون تعقيبى شفه مورد تجزيه و تحليل قرار گرفت. يافتهها: نتايج نشان داد از نظر متغير دموگرافيك هيج گَنه تفاوت معنادارى در ميان دو گروه مداخله و كنترل قبل از مطالعه مشاهده نكرديد (ه • • P>)، بين ميانگين نمرات توانمندى بيمار و توانمندى عضو فعال خانواده و تبعيت از درمان

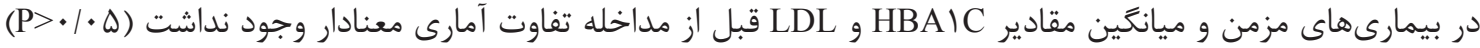
اما بعد از مداخله، به غير از ميزان LDL در بقيه موارد اختلاف آمارى معنادارى بين دو گروه مشاهده شد (ه •|•>P). بحث و نتيجهكيرى: نتايج مطالعه حاكى از اثرات مثبت اجراى التوى توانمند سازى خانواده محور بر افزايش تبعيت از درمان در بيماران بود.

كلمات كليدى: اختلالات قلبى، الكوى توانمند سازى خانواده محور، تبعيت از درمان، ديابت نوع r.

تاريخ دريافت: تاريخ يذيرش:

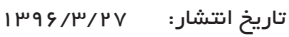

با عوارض ناتوان كننده است كه سير مزمن و نامحسوس داشته

مقدمه

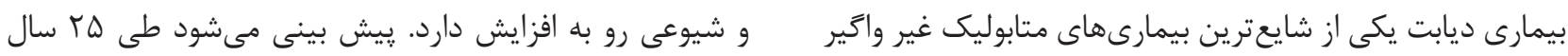

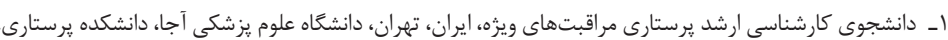

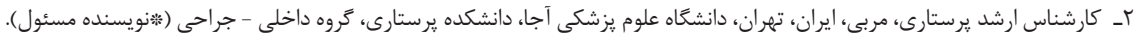
آدرس الكترونيك: Marjanmazhari@yahoo.com

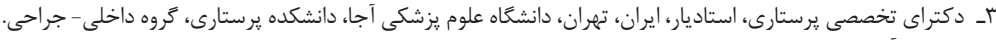

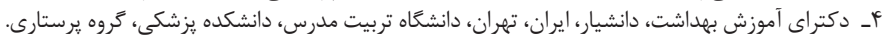


(1F) (1). از اين رو آموزش و توانمندسازى بيمار و خانواده جهت خود مراقبتى و تبعيت مطلوب از توصيههاى درمانى، كنترل متابوليكى

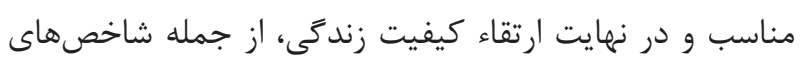

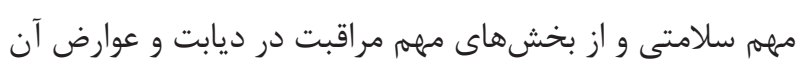

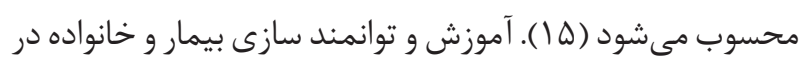

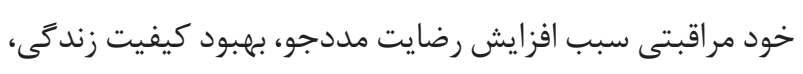

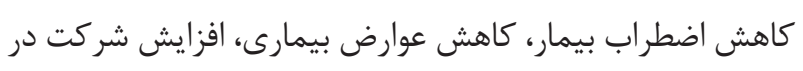

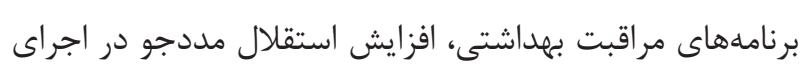

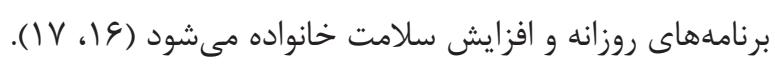

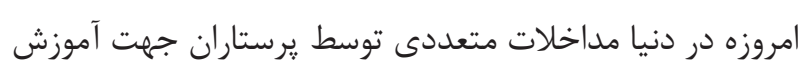
رفتارهاى خود مراقبتى، تبعيت از درمان و ارتقاء سلامت بيماران

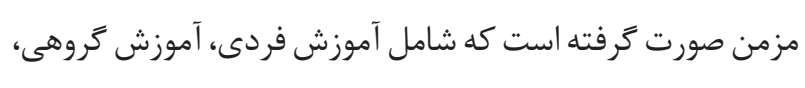

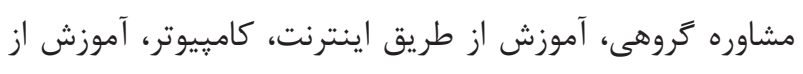

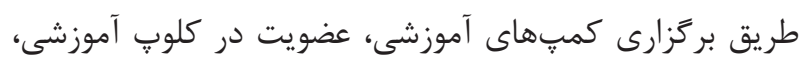

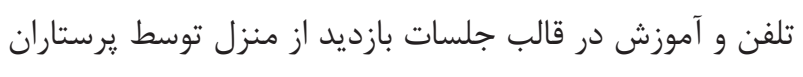

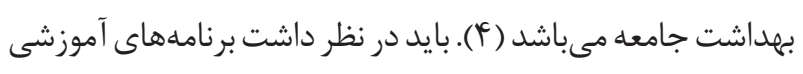

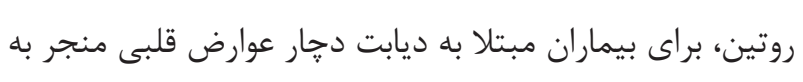

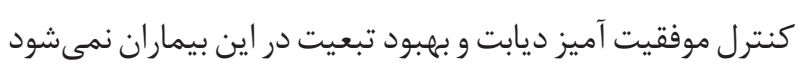

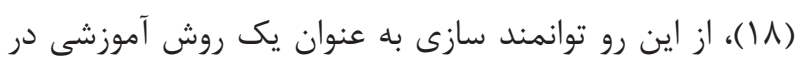

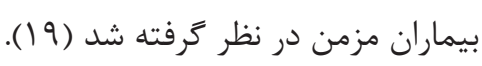

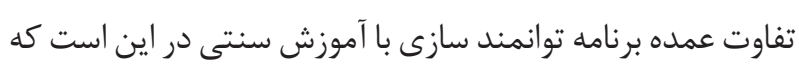

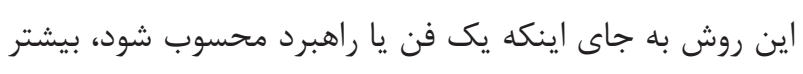

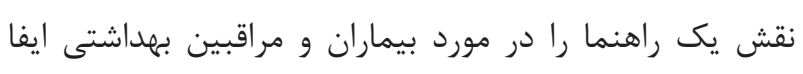

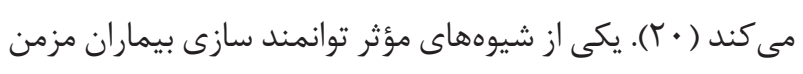

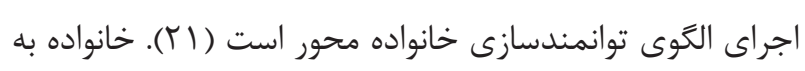

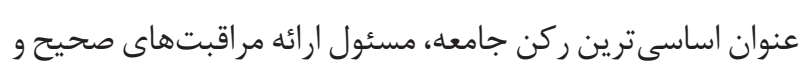

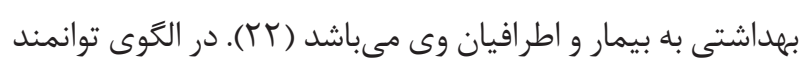

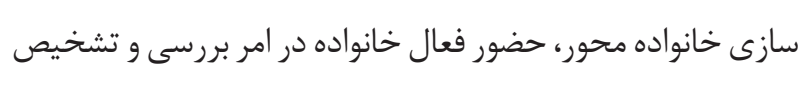

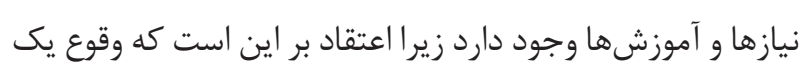

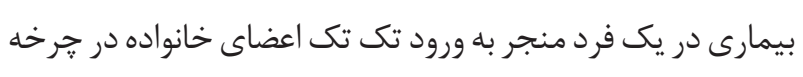

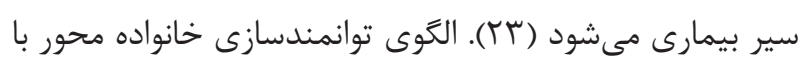

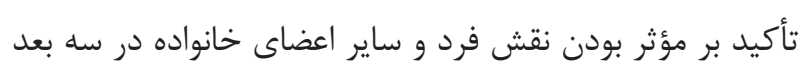

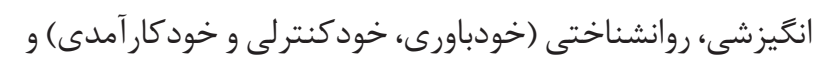

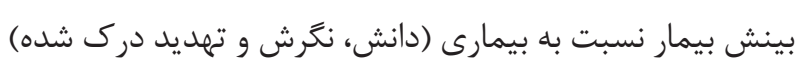

آينده جزء مهمترين عوامل مرگ و ناتوانى در دنيا محسوب شود

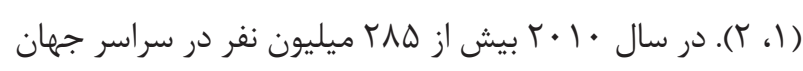

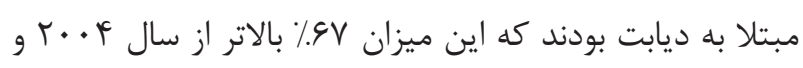

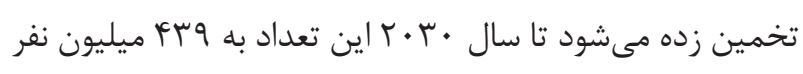

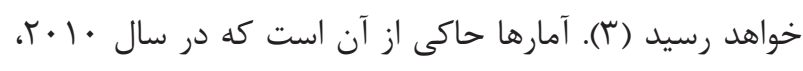

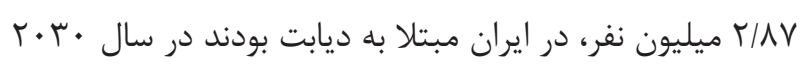

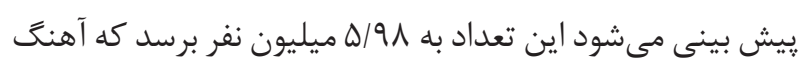

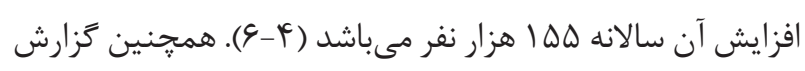

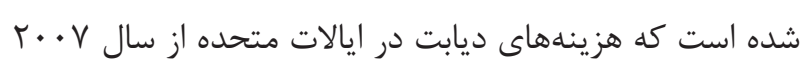

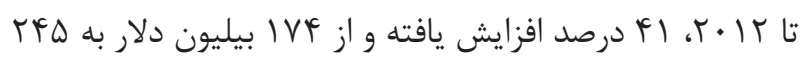

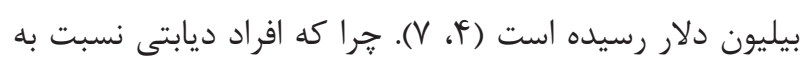

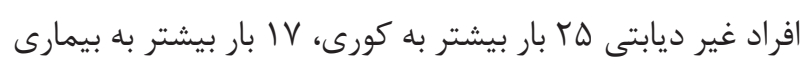

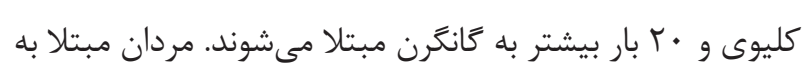

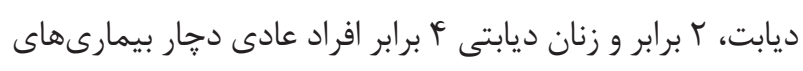
عروق كرونر مىشوند، همجنين احتمال سكته مغزى در آنها

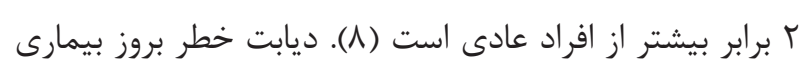

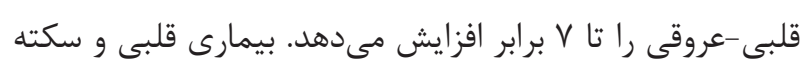

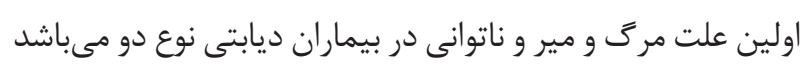

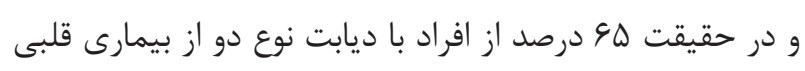
يا سكته قلبى مىميرند (9). با توجه به ماهيت بيمارى و عوارض درازمدت، ديابت در زمره اختلالات مزمن دستهبندى مىشود كه درمان قطعى ندارد اما

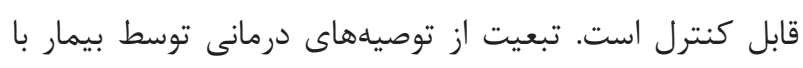

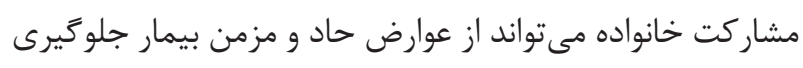

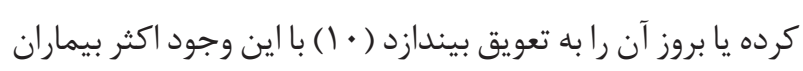

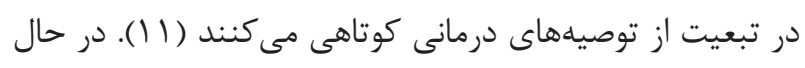

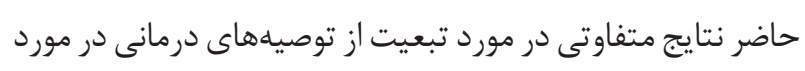

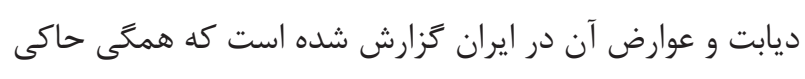

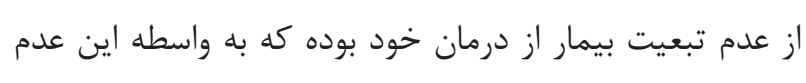

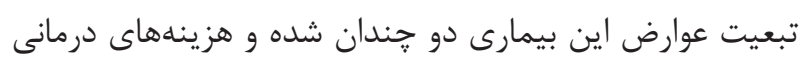

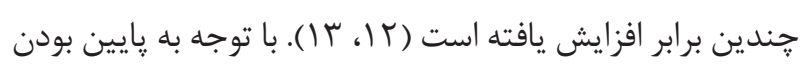

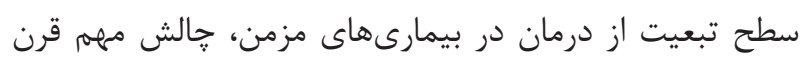

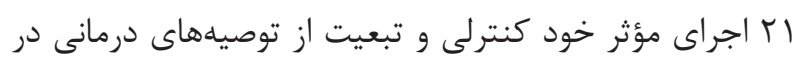

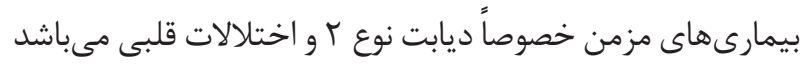




$$
n=\frac{\left(1 / 1 \Lambda^{r}+1 / \Lambda \Lambda^{r}\right)(1 / r+r / \Delta V)^{r}}{(\Lambda / q r-v / \cdot r)^{r}}=r v / r \Delta
$$

شرايط ورود به مطالعه عبارت بودند از: تشخيص ديابت حداقل از 9

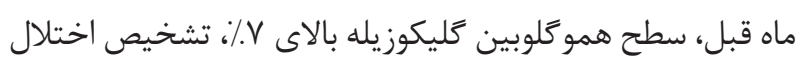

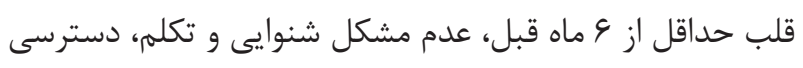

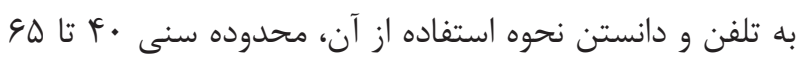

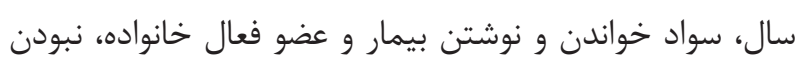

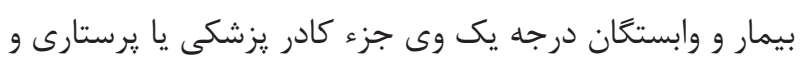

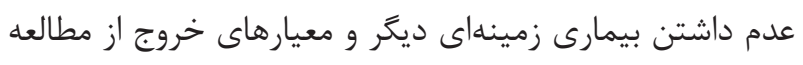

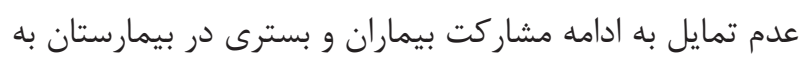

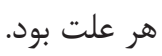
در اين يزوهش ابزار جمعآورى دادها شامل يرسشنامه اطلاعات

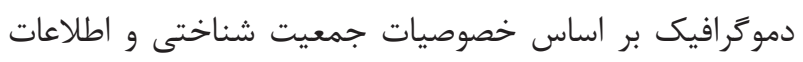
مربوط به بيمارى، يرسشنامه توانمندى شامل حيطه تهديد درى

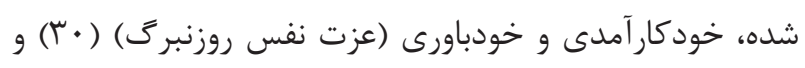

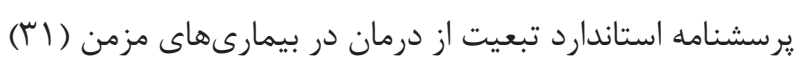

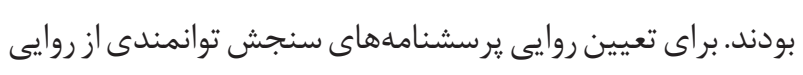

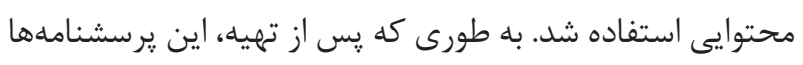

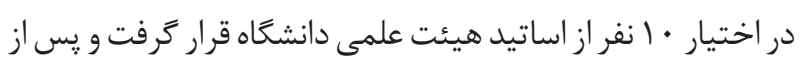

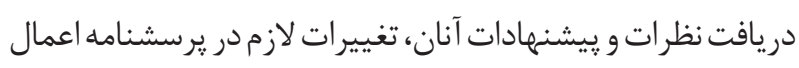

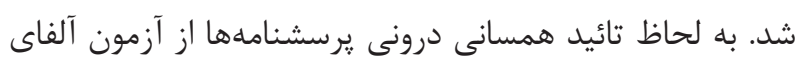

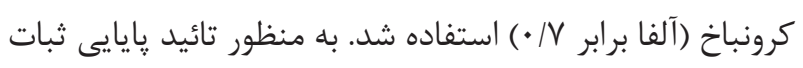

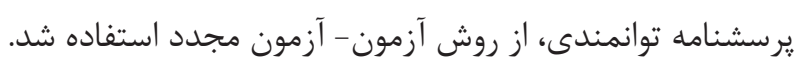

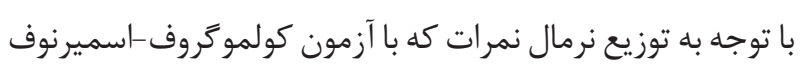

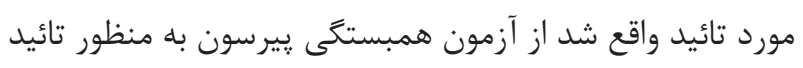

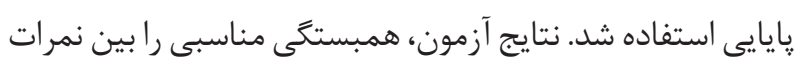

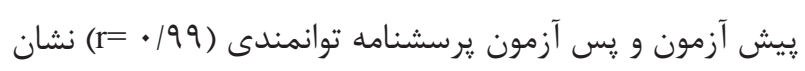

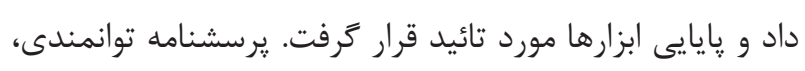

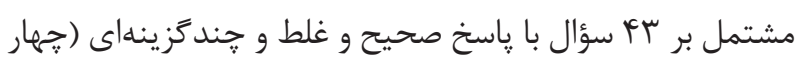
جوابى) و موافق و مخالف به صورت تركيبى بود. حيطه تهديد

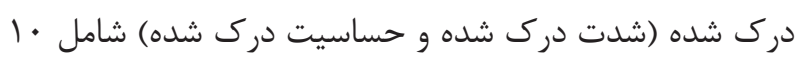

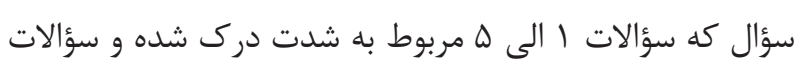

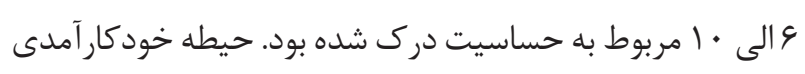

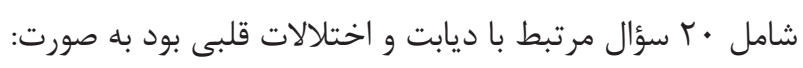

طراحى شده است (TI) و مىتواند الكوى مناسبى براى ارتقاء

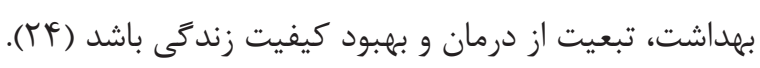

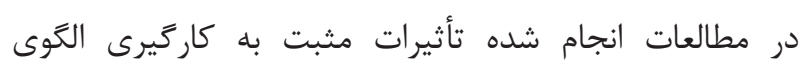

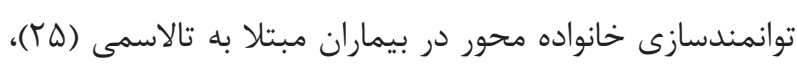

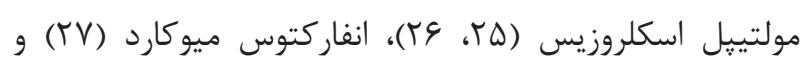

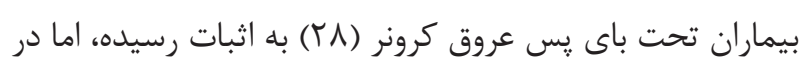

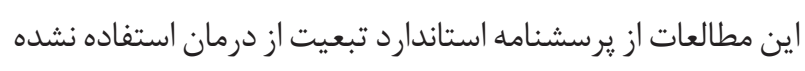
است اين در حالى است كه در مطالعه حاضر كه با هدف تعيين تأثير بكاركيرى الكَوى توانمندسازى خانواده محور بر تبعيت از درمان

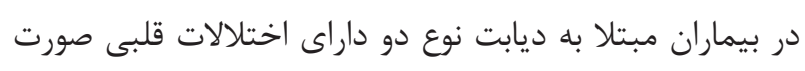
يذيرفت از يرسشنامه استاندارد تبعيت از درمان استفاده شده است.

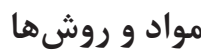

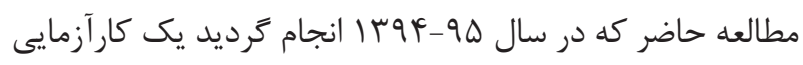

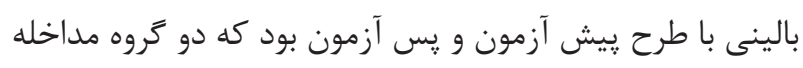

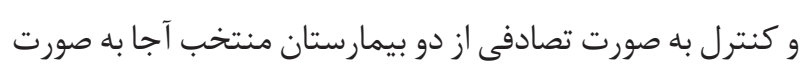
مبتنى بر هدف انتخاب شدند و با يكديكر مورد مقايسه قرار كرفتند. جامعه هدف در اين مطالعه بيماران ديابتى نوع دو مبتلا

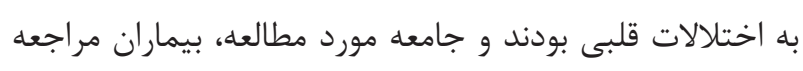
كننده به كلينيك ديابت و كلينيك غدد دو بيمارستان منتخب

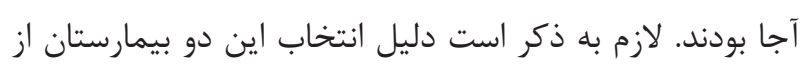
آن جهت بود كه طبق تحقيق يزوهش آنر بيشترين آمار اين گَونه

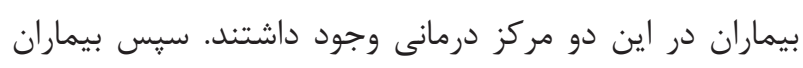

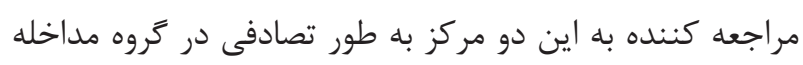

$$
\text { و كنترل قرار كرفتند. }
$$

محاسبه حجم نمونه با توجه به يروهش مشابه انجام شده (YN)

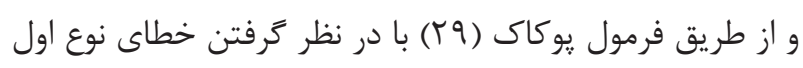

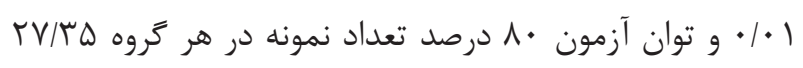

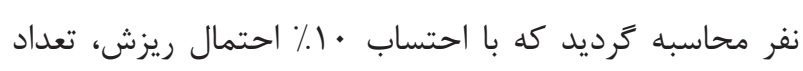

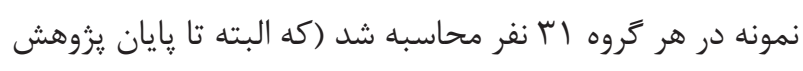

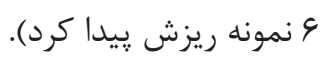

$$
n=\frac{\left(s_{1}^{r}+s_{r}^{r}\right)\left(z_{1-\frac{\alpha}{r}}+z_{1-\beta}\right)^{r}}{\left(\bar{X}_{1}-\bar{X}_{r}\right)^{r}}
$$




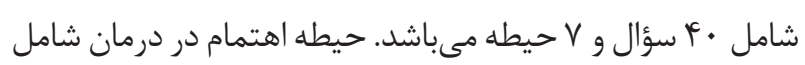

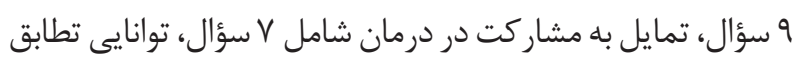

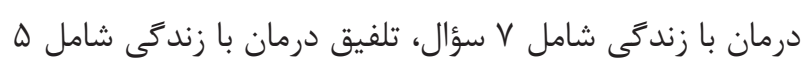

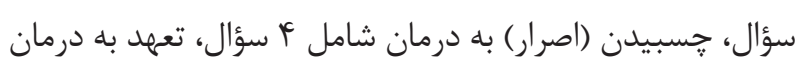

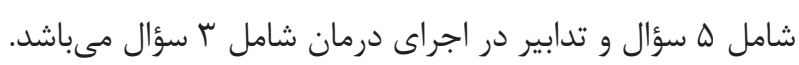

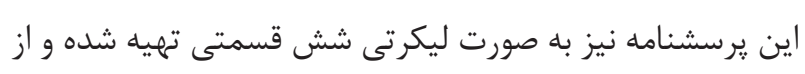

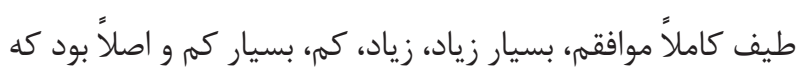

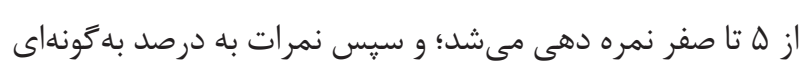

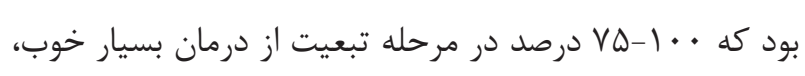

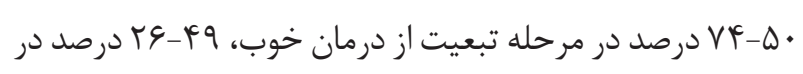

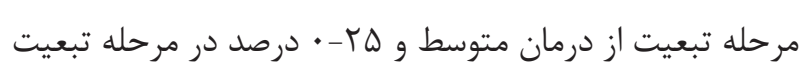
از درمان ضعيف قرار داشت.

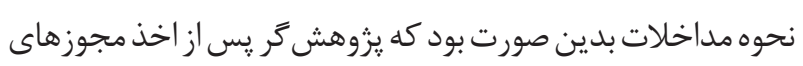

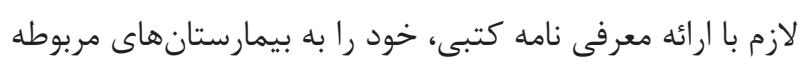

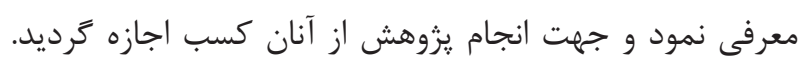

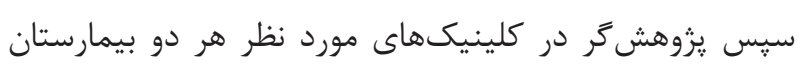

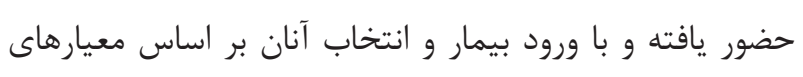
يروهش خود را به واحدهاى مورد يزوهش معرفى و موافقت آنان

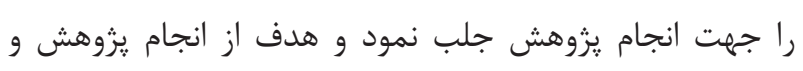

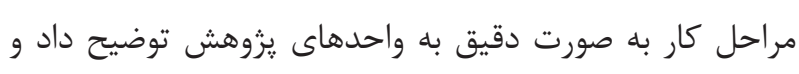

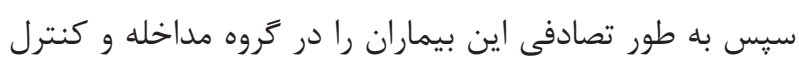

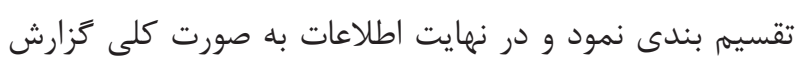

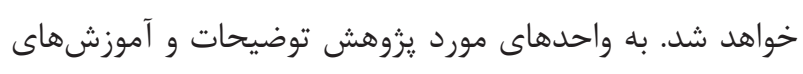

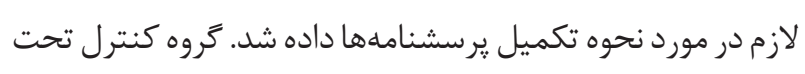

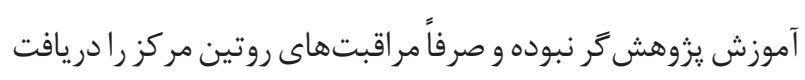

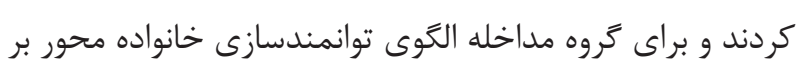

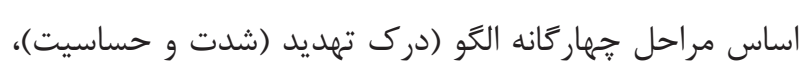

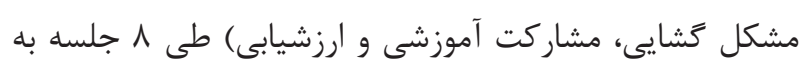
صورت آموزش گروهى و هر هفته يك جلسه برگزار شد. جلسات

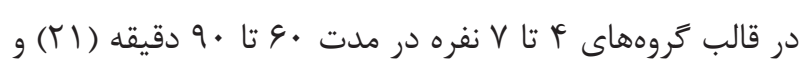
كام الكو به ترتيب زير بود.

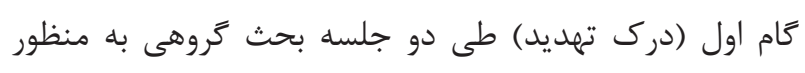
بالا بردن آكاهى و حساس سازى بيماران صورت كرفت. كام
خود كار آمدى كنترل فشار خون شامل ه سؤال (سؤالات 11 الى ها ). خودكار آمدى كلوكومترى و تزريق انسولين شامل 9 سؤال

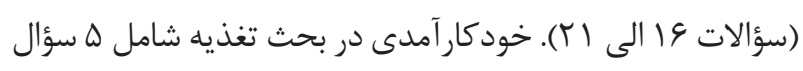

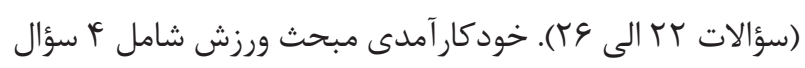

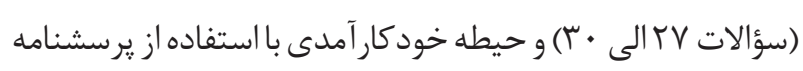

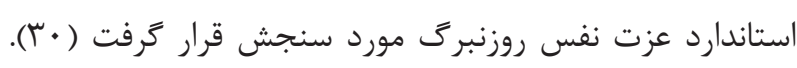

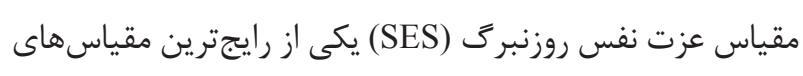

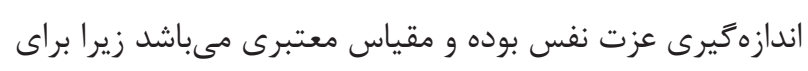

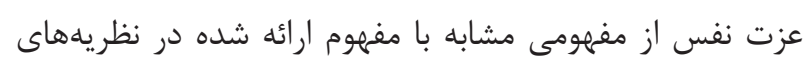

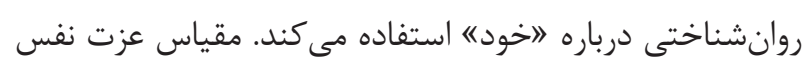

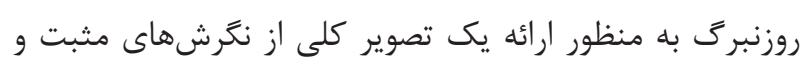

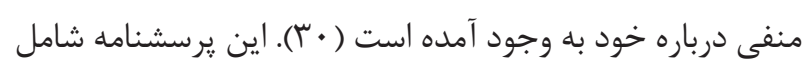

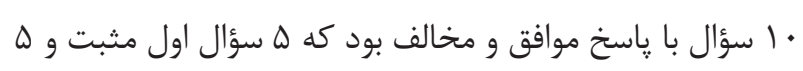

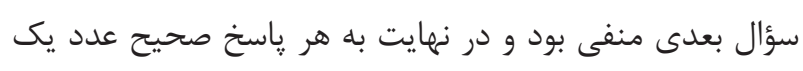

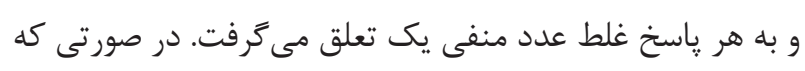

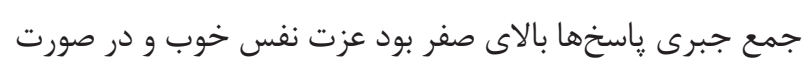

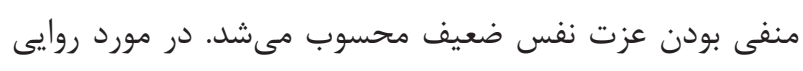

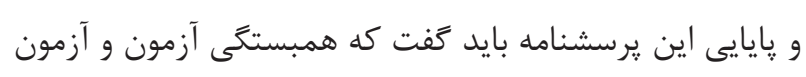

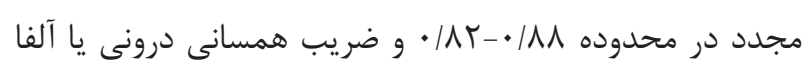

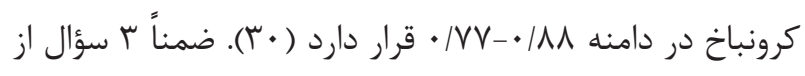

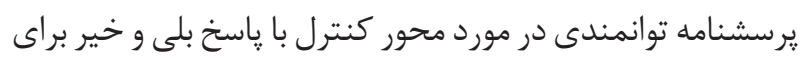

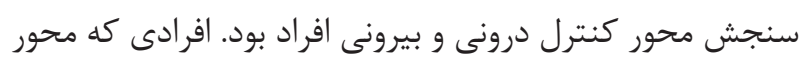

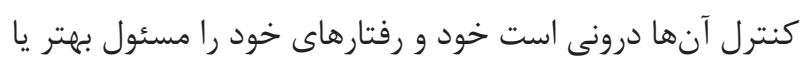

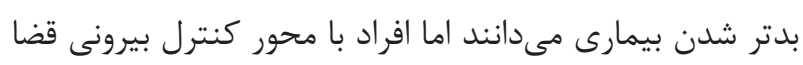
و قدر الهى و مشيت را مسئول بيمارى و عوارض مى دانند ( (T).

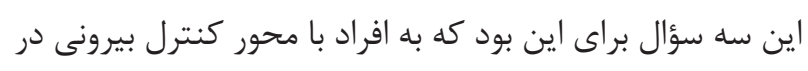

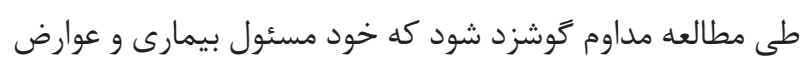

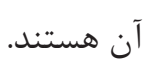
لازم به ذكر است يرسشنامه استاندارد تبعيت از درمان در

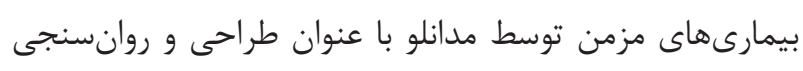

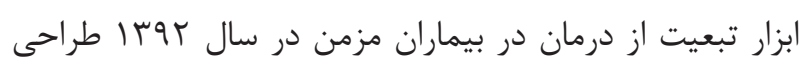

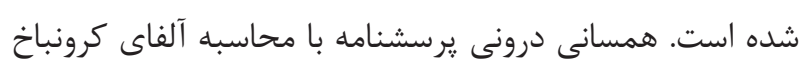

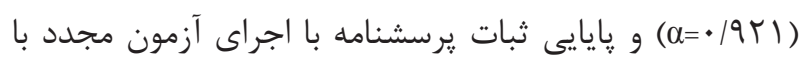

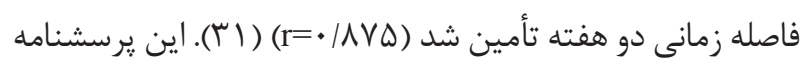


جلسه دو ساعته موارد مرتبط با الكو به كروه كنترل نيز آموزش

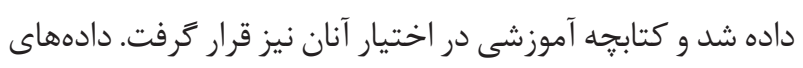

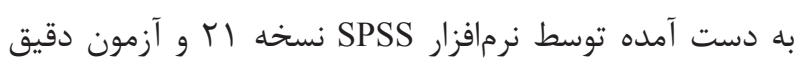

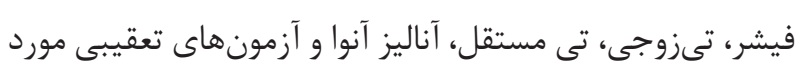

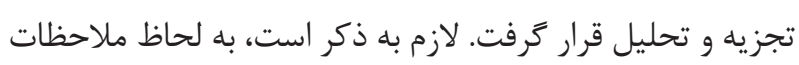

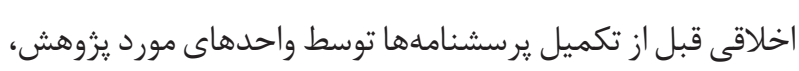
ضمن اخذ رضايت كتبى از بيماران و عضو فعال خانواده آنان،

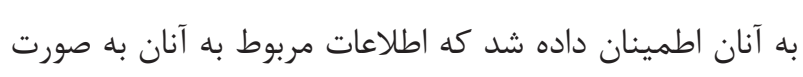

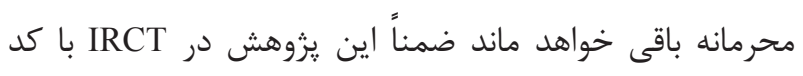
و دانشعاه علوم يزشكى آجا با كد

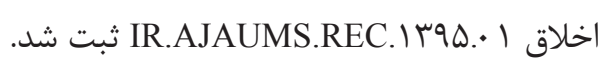

يافتهها در مطالعه فوق تعداد ك بو نفر از بيماران ديابت نوع دو مبتلا به

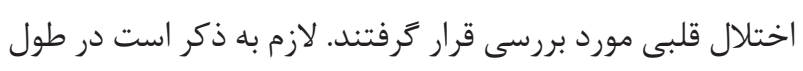

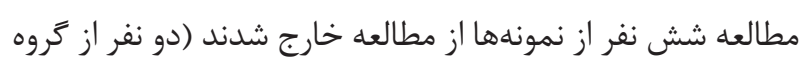

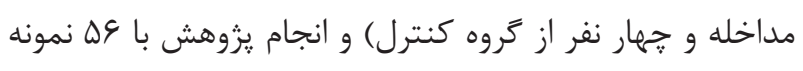
״ايان يذيرفت. ميانكَين سن در كروه مداخله

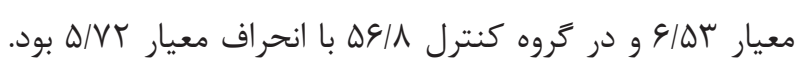
بيشترين فراوانى را در هر دو كروه از نظر جنس مردان

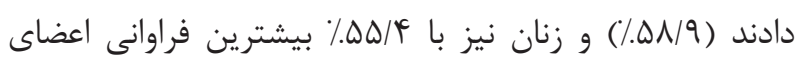
فعال خانواده را تشكيل مى دادند. از نظر سطح تحصيلات نمونهها،

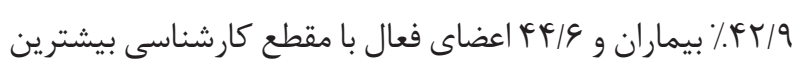

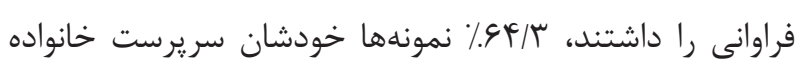

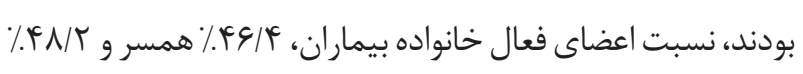

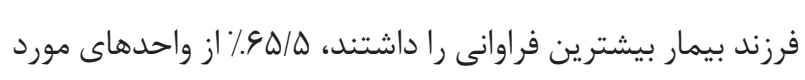
يروهش در كروه مداخله و بعد درصد در كروه كنترل تزريق انسولين نداشتند؛ يافتههاى اين يزوهش نشان داد كه بيماران دو مر مروه مداخله و كنترل از نظر مشخصات فردى همكن بودند (جدول (1).

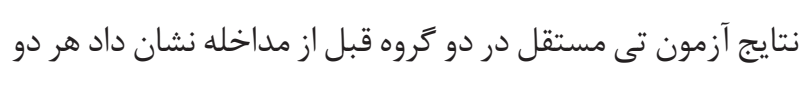

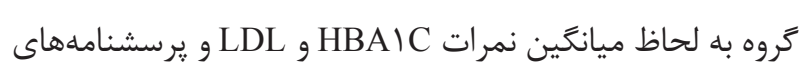
توانمندى و تبعيت از درمان تفاوت آمارى معنادارى ندارند (ه • • •)؛

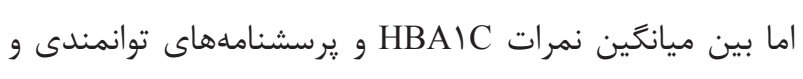
تبعيت از درمان بعد از مداخله اختلاف آمارى معنادارى مشاهده
شد. بيماران در اين جلسات تحت نظارت يزوهشكر در ارتباط با

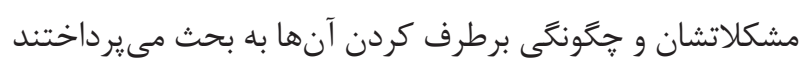

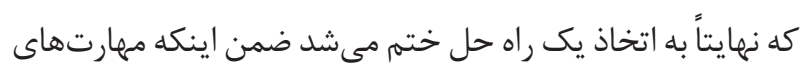

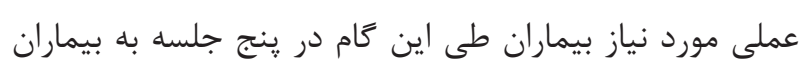
آموزش داده مىشد. محوريت جلسات در اين كام شامل موضوعات تغذيه، ورزش، دارودرمانى، كلوكومترى و تزريق انسولين و كنترل فشار خون بود كه هر مبحث طى يك جلسه بركزار شد. در كام

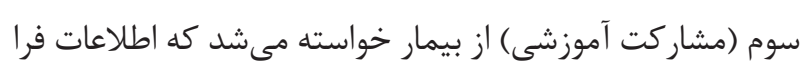

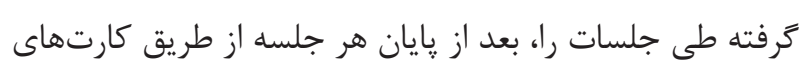

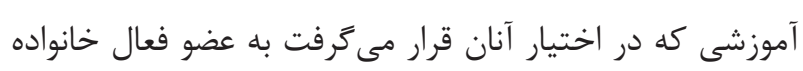

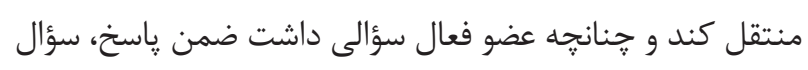

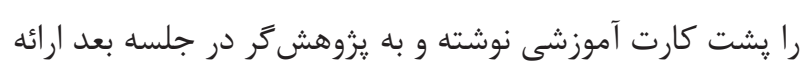

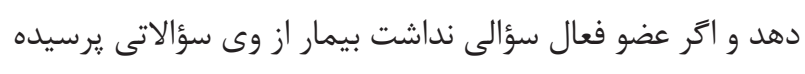

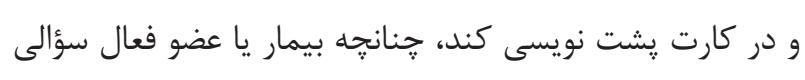

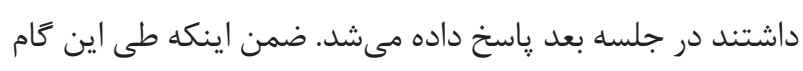
كتابجه آموزشى ديابت كه از قبل، طراحى شده بود در در اختيار

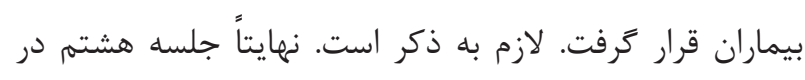

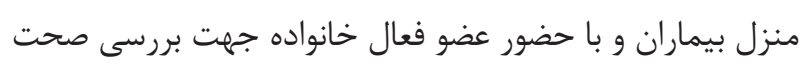

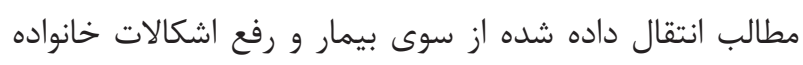

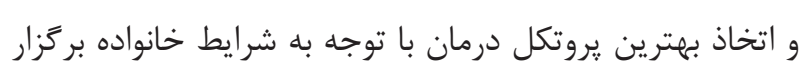
شد، شماره تماس يزوهش

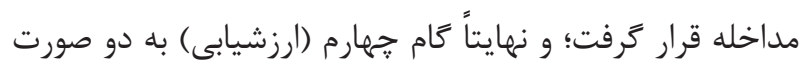

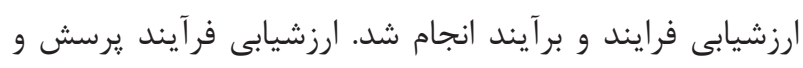

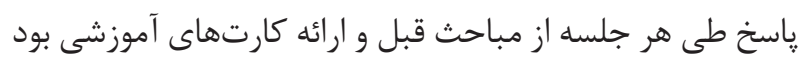

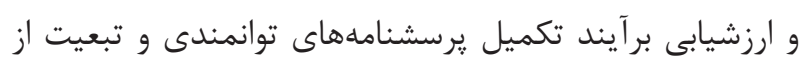

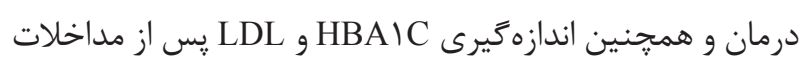

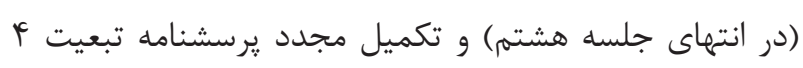

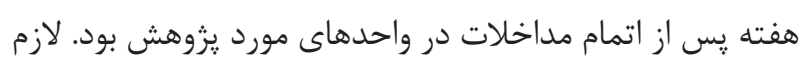

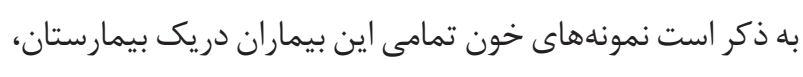

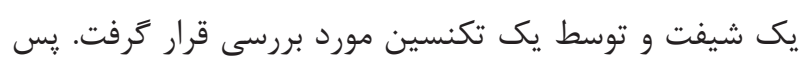

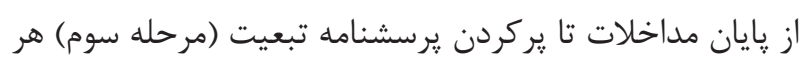

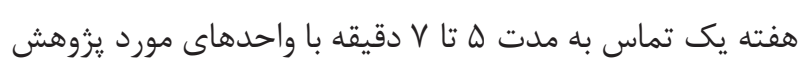

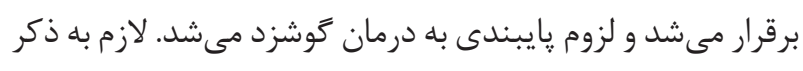

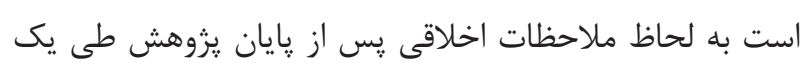


جدول ا - مشخصات فردى واحدهاى مورد يثوهش

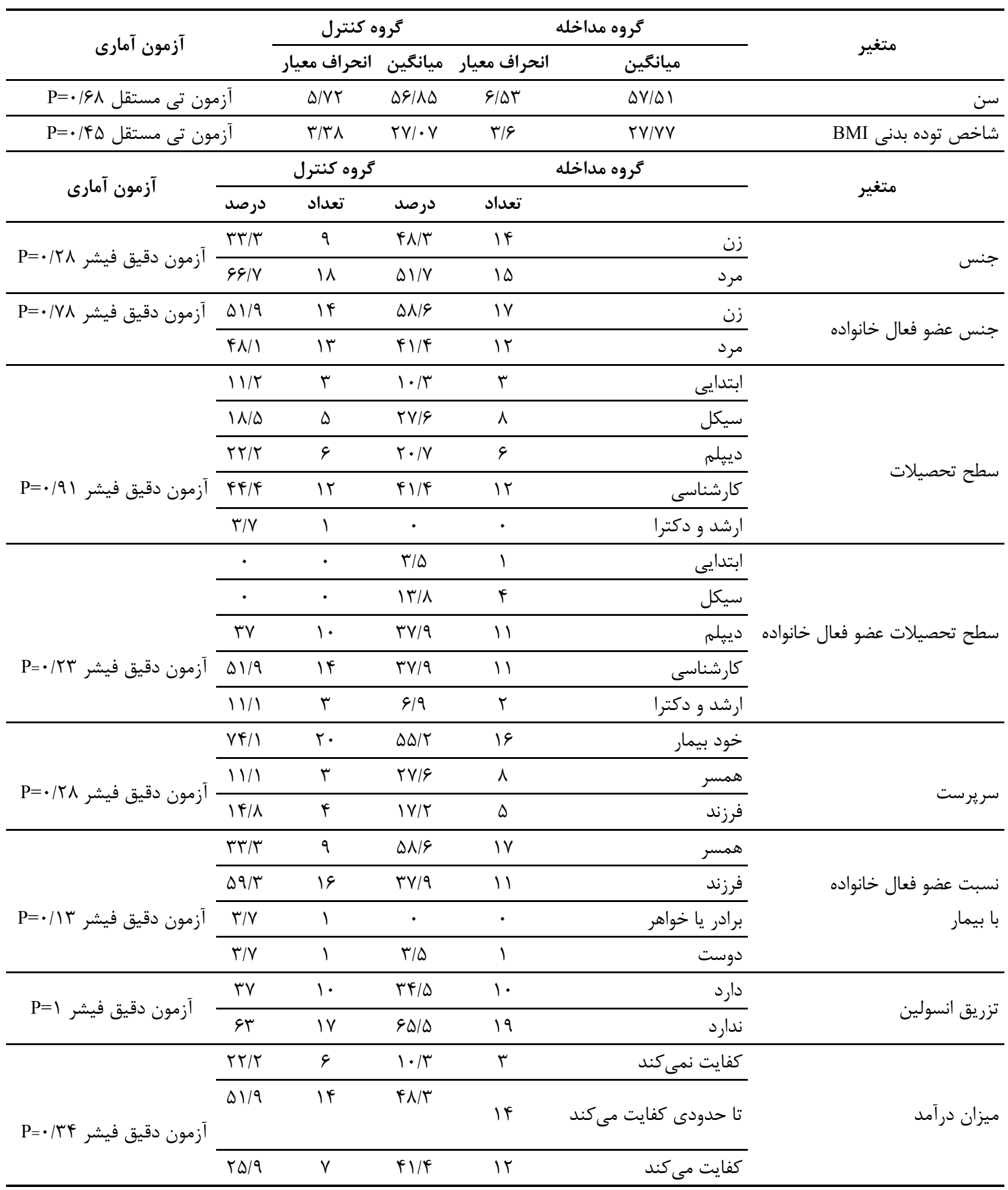

نتايج آناليز اندازهاى تكرارى (آنوا) و آزمون تعقيبى براى يرسشنامه تبعيت از درمان بيمارىهاى مزمن نشان داد مقايسه

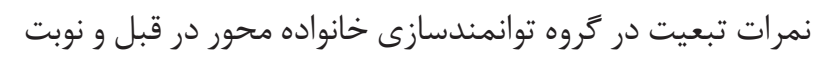

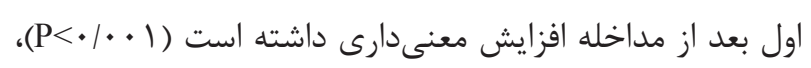

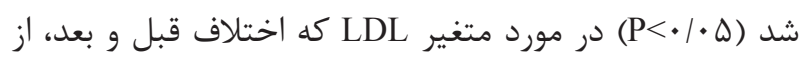

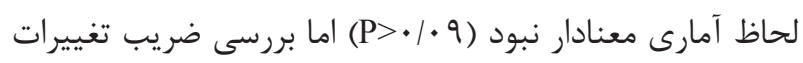
حاكى از كاهش زشمعير LDL در كروه مداخله نسبت به مَروه

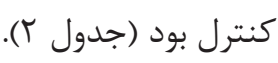


جدول r - مقايسه ميانكَين و انحراف معيار نمرات هموَلوبين كَليكوزيله، LDL، توانمندى، قبل و بعد از مداخله بين دو كروه مداخله و كنترل در بيماران و عضو فعال

\begin{tabular}{|c|c|c|c|c|c|}
\hline \multicolumn{4}{|c|}{ كروه } & & \multirow{3}{*}{ متغير } \\
\hline \multicolumn{2}{|c|}{ آزمون تى مستقل } & كنترل & مداخله & & \\
\hline & & ميانغين+|نحر اف معيار & ميانگين土|نحراف معيار & & \\
\hline $\mathrm{t}=1 / \mathrm{r}$ & $\mathrm{P}=\cdot / \mathrm{r}$ & $q r / q 9 \pm r r / \cdot \Delta$ & 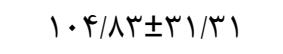 & قبل & \multirow{2}{*}{ LDL } \\
\hline $\mathrm{t}=-1 / 1 \mathrm{~V}$ & $\mathrm{P}=\cdot 1 \cdot 9$ & $q r / F \pm r r / r q$ & $\Lambda \cdot / I r \pm r \Delta / r V$ & بعد & \\
\hline$t=-\cdot / 1 \Delta$ & $\mathrm{P}=\cdot \mid \wedge \Lambda$ & $\Lambda / 4 I \pm \cdot / \Lambda q$ & $\Lambda / r V \pm 1 / \cdot r$ & قبل & \multirow{2}{*}{$\mathrm{HbAlC}$} \\
\hline $\mathrm{t}=-\Delta / \varepsilon \mathrm{q}$ & $\mathrm{P}=\cdot / \cdots$ & $\mathrm{V} / 9 \mathrm{~V} \pm \cdot / \Lambda \Lambda$ & $9 / 14 \pm \cdot 109$ & بعد & \\
\hline $\mathrm{t}=-1 / \Delta \mathrm{V}$ & $\mathrm{P}=\cdot / 1 \mathrm{r}$ & IV/rTEg/fr & $\mid F / V T \pm \Delta / q r$ & قبل & \multirow{2}{*}{ توانمندى } \\
\hline $\mathrm{t}=1 \cdot / T / \mathrm{F} T$ & $\mathrm{P}=\cdot / \cdots$ & $19 / \Delta \mid \pm \xi / \Gamma \wedge$ & $\Delta / \Gamma \wedge \pm \Gamma \Delta / \Delta \Lambda$ & بعد & \\
\hline $\mathrm{t}=-\cdot / \mathrm{V}$ & $\mathrm{P}=\cdot / \cdot \wedge$ & $|r| \Lambda \mid \pm F / \cdot r$ & $r / q \Delta \pm \mid r / F q$ & قبل & \multirow{2}{*}{ توانمندى عضو فعال } \\
\hline$t=r / 91$ & $\mathrm{P}=\cdot / \cdots$ & 19/•VIq/Kr & $r / \mid \Delta \pm r \wedge / \Delta \Lambda$ & بعد & \\
\hline
\end{tabular}

است ميانگين افزايش نمرات در گروه مداخله بسيار خشمخيرتر از زروه كنترل مىباشد.

\section{بحث و نتيجهَ}

بيمارى ديابت يكى از شايعترين بيمارىهاى قرن حاضر بوده كه هر سال تعداد بىشمارى را درگير عوارض خطرناك خود مىنمايد. عوارض خطرناكى كه نه تنها بار مالى بىشمارى بر دوش خانواده و جامعه مى گذارد بلكه سبب مرگ و مير بسيار زيادى هم مى شود يكى از اين عوارض اختلال قلبى مىباشد كه كنترل آن تبعيت از درمان بيمار و خانواده را مىطلبد (ب). در اين راستا الگوى توانمندسازى خانواده محور مورد بررسى قرار گرفت تا اثربخشى اين الكو در تبعيت از درمان مورد بررسى قرار گيرد. اين يزوهش با
همجنين بين تبعيت قبل از مداخله و جهار هفته يس از مداخله هم تفاوت معنى دارى وجود دارد ( ( P< (P) ولى بين نمرات تبعيت بعد از مداخله و نمرات تبعيت جهار هفته يس از مداخله

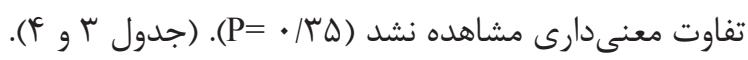

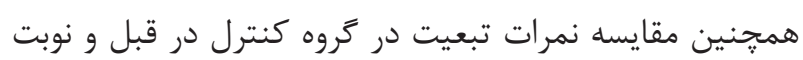

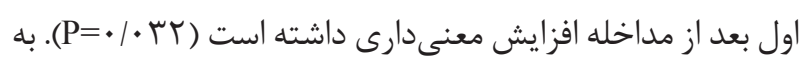
علاوه بين تبعيت قبل از مداخله و تهار هفته يس از مداخله هم

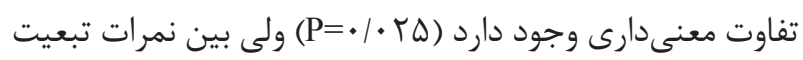
بعد از مداخله و جههار هفته يس از مداخله تفاوت معنىدارى مشاهده نشد ( آ/ • P=). در كل با توجه به آناليز اندازههاى تكرارى (جدول آنوا) اگرجه ميانگين افزايش نمرات در هر دو گروه در سه زمان معنى دار بوده است ولى همانطور كه از آمارها مشخص

جدول بـ جدول مقايسه ميانَين و انحراف معيار نمرات بر سشنامه تبعيت از درمان در سه مقطع قبل از مداخله، بعد از مداخله و جههار هفته پِ از مداخله

\begin{tabular}{|c|c|c|c|c|}
\hline \multirow{3}{*}{ RM ANOVA } & \multicolumn{3}{|c|}{ متغير } & \multirow{3}{*}{ تروه } \\
\hline & Fفته يس از مداخله P F & بعد از مداخله & قبل از مداخله & \\
\hline & ميانگين士|نحراف معيار & ميانغين土|نحر اف معيار & ميانگين士|نحر اف معيار & \\
\hline$F=r T V / \mathcal{F}$ & \multirow{2}{*}{$19 V / T V \pm 1 \mid / 9 \Lambda$} & \multirow{2}{*}{$1 \varepsilon \wedge / \Delta \Delta \pm 9 / 9 \Delta$} & \multirow{2}{*}{ 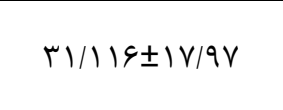 } & \multirow{2}{*}{ مداخله } \\
\hline $\mathrm{P}=\cdot / \cdots$ & & & & \\
\hline$F=f / f q$ & \multirow{2}{*}{$\mid r \Delta / r T \pm I V / \Lambda$} & \multirow{2}{*}{$|r T / V V \pm| N / 9 \Delta$} & \multirow{2}{*}{$119 / \wedge \Lambda \pm r \cdot / \Lambda r$} & \multirow{2}{*}{ كنترل } \\
\hline \multirow[t]{3}{*}{$\mathrm{P}=\cdot / \cdot r F$} & & & & \\
\hline & $\mathrm{T}=\Lambda / \cdot 1 \Delta$ & $\mathrm{T}=\Lambda / \mathrm{\wedge} \wedge$ & $\mathrm{T}=-1 / 91$ & \multirow{2}{*}{ آزمون تى مستقل } \\
\hline & $\mathrm{P}=\cdot / \cdots$ & $\mathrm{P}=\cdot / \cdots$ & $\mathrm{P}=. \mid \cdot 91$ & \\
\hline
\end{tabular}




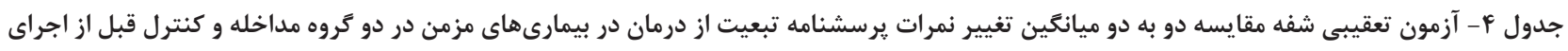

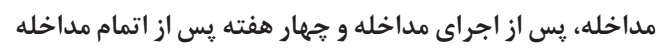

\begin{tabular}{|c|c|c|c|c|}
\hline Mean Difference $=-\Delta T / T Y$ & $\mathrm{P}<\cdot 1 \cdots 1$ & بعد از مداخله & قبل از مداخله & نتيجه آزمون \\
\hline Mean Difference $=-\Delta) / \cdot \varphi$ & $\mathrm{P}<\cdot / \cdot \cdot 1$ & F أ هفته بعد از مداخله & قبل از مداخله & تعقيبى كروه \\
\hline Mean Difference $=1 / \mathrm{V}$ & $\mathrm{P}=\cdot / \mathrm{r} \omega$ & F أ هفته بعد از مداخله & بعد از مداخله & 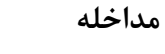 \\
\hline Mean Difference $=-r / \Lambda \Lambda$ & $\mathrm{P}=\cdot / \cdot r r$ & بعد از مداخله & قبل از مداخله & نتيجه آزمون \\
\hline Mean Difference $=-\Delta / \mathcal{} \in \mathcal{F}$ & $\mathrm{P}=\cdot / \cdot r \Delta$ & F أ هفته بعد از مداخله & قبل از مداخله & تعقيبى كروه \\
\hline Mean Difference $=-1 / \Delta \Delta$ & $\mathrm{P}=\cdot / \mu / f$ & F أ هفته بعد از مداخله & بعد از مداخله & كنترل \\
\hline
\end{tabular}

" مشخص شد كه قبل از مداخله بين دو گروه تفاوت معنى دارى

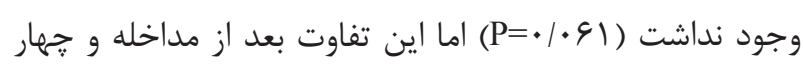
هفته يس از مداخله معنى دار بود به طورى كه تبعيت از درمان

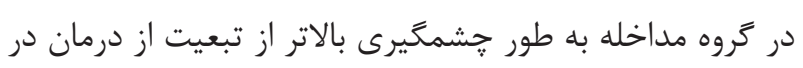

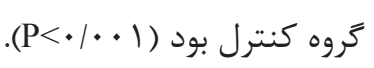

هم راستا با يافتههاى يزوهش حاضر، مبنى بر تأثير مثبت اجراى الكوى توانمندسازى خانواده محور بر تبعيت از درمان يافتههاى

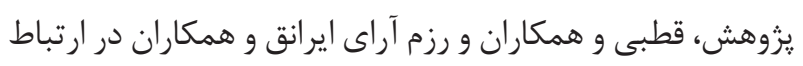
با تأثير آموزش خانواده محور بر رعايت رزيمم درمانى افراد مبتلا به ديابت نشان داد كه بعد از مداخله رعايت رزيم درمانى بين دو

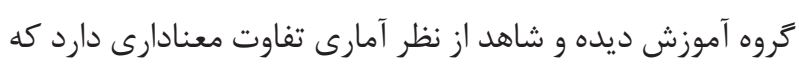
اين امر حاكى از تأثير مثبت آموزش در بعد رزيم غذايى در گروه

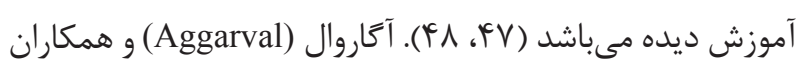
در يك كارآزمايى خانواده محور تحت عنوان حمايت اجتماعى يايين و ارتباط آن با عدم تبعيت از رزيم غذايى در طول يك سال

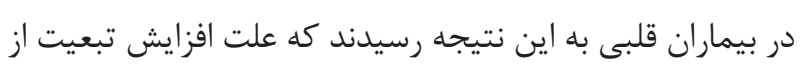
رزيم غذايى، حضور خانواده در كنار بيمار و افزايش توانايى مديريت بيمار جهت يايش شرايط جسمى و افزايش سطح خودكارآمدى رئ است (\$q). نتايج تحقيقات ثنايى و همكار ان در بررسى تأثير اجراى مدل توانمند سازى خانواده محور بر تبعيت از درمان در بيماران باى پس كرونر نشان داد اجراى الگُى توانمندسازى خانواده

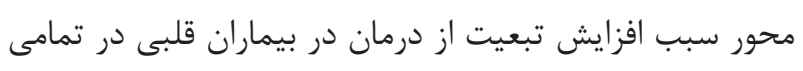
زمينههاى درمان شده است (YN) و مشاركت اعضاى خانواده به عنوان مهرمترين عامل خارجى در افزايش سطح عملكرد و تبعيت به طور مستمر و مداوم حائز اهميت است. مطالعه حكيم و همكاران
هدف كلى تعيين تأثير الكوى توانمند سازى خانواده محور بر تبعيت از درمان در بيماران ديابتى نوع دو داراى اختلالات قلبى مراجعه كننده به بيمارستانهاى منتخب آجا انجام گرفت. يافته داى اين يزوهش حاكى از آن است كه در قبل از مداخله در دو گروه به لحاظ مؤلفههاى يرسشنامهها تفاوت آمارى معنادارى نداشت

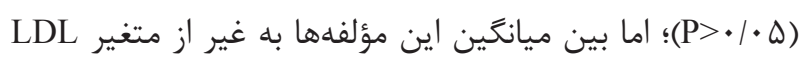

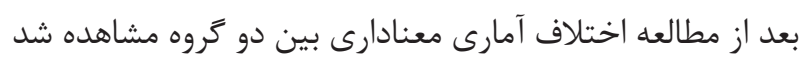
(P< • P (P). بررسى ضريب تغييرات نشان دهنده كاهش جشمخير د د ₹روه مداخله نسبت به گروه كنترل بود. محققان معتقدند توانمندسازى بيماران در مورد بيمارى و كنترل آن اهميت زيادى داشته و بر كنترل بيمارى مؤثر است (Tس). مطالعه محققان نشان داد آموزش به بيمار ديابتى باعث مىشود

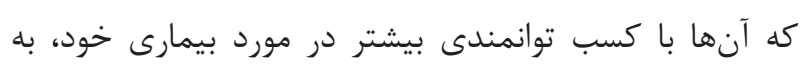
توصيه هاى ارائه شده براى كنترل و مديريت بيمارى بيشتر توجه بيه بئن نموده و به صورت فعالترى در مديريت بيمارى خود درگير شوند

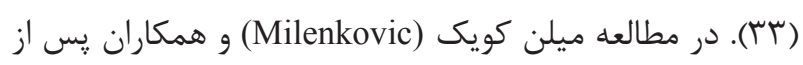
يك سال دانش و توانمندى آنان به طور معنادارى افزايش يافت (YL)، در مطالعه ساير محققين نيز مشخص شد يس از اجراى الكوى توانمندسازى خانواده محور توانمندى و عزت نفس بيماران

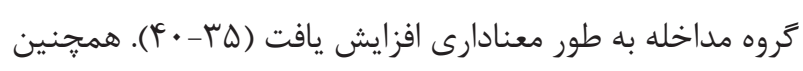
يزوهش برخى از محققان در مورد مداخلات خانواده محور بر روى شاخص متابوليك نشان از بهبود شاخصها يس از مطالعات

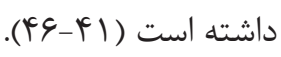

در راستاى اهداف مقايسه ميزان تبعيت از رزيمم درمانى قبل و بعد

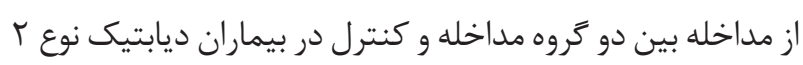
دار اى اختلالات قلبى مر اجعه كننده به بيمارستان هاى منتخب آجا 
مداخله و كنترل معنى دار است اما اين معنى دارى باز هم به طور

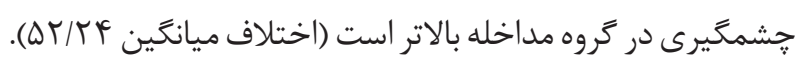

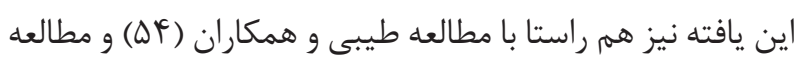
موسوى فر و همكاران (هل) مىباشد.

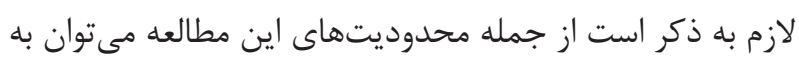

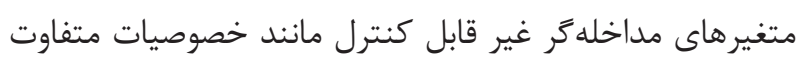

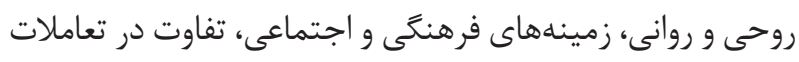

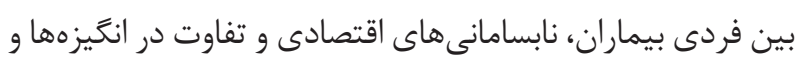
علايق شخصى واحدهاى مورد يزوهش اشاره كرد كه مى توانست

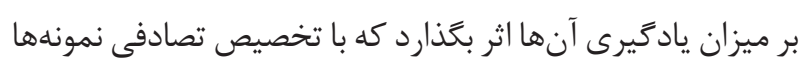

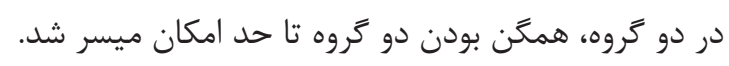

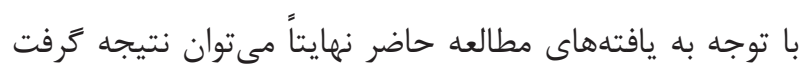

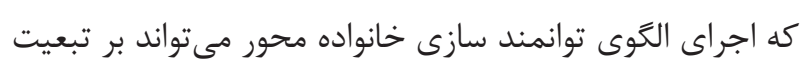

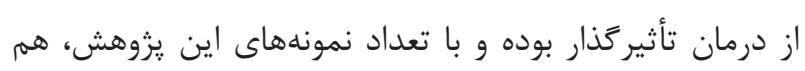

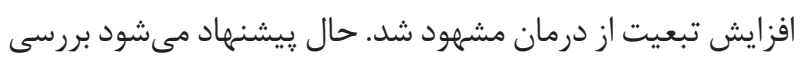

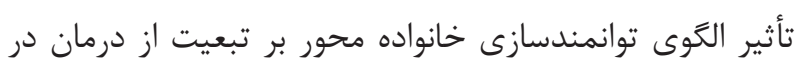
ديابت و اختلالات قلبى و ساير بيمارىهاى مزمن با حجم نمونه

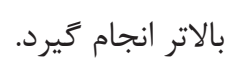

\section{تشكر و قدردانى}

اين مقاله بركرفته از پاياننامه كارشناسى ارشد رشتى رشته يرستارى

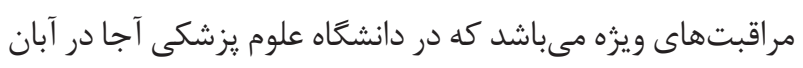

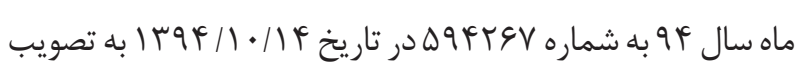
رسيده و هزينه انجام آن از طريق دانشعاه علوم يزشكى آجا تأمين

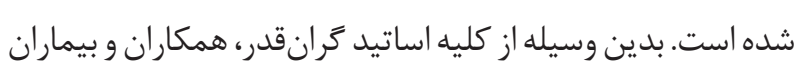
ارجمند شركت كننده در طرح تشكر و قدردانى به عمل مئ آيد.

\section{References}

1- Ding CH, Teng CL, Koh CN. Knowledge of diabetes mellitus among diabetic and non-diabetic patients in Klinik Kesihatan Seremban. Med J Malaysia. 2006;61(4):399-404. PMID: 17243515

2- Smeltzer S, Bare B. Brunner \& Suddarth>s textbook of medicalsurgical nursing. Philadelphia: Lippincott Williams \& Wilkins; 2010 .
آموزش ديده از نظر فعاليتهاى ورزشى و انطباق با درمان وجود

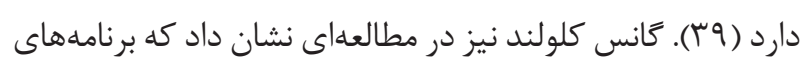

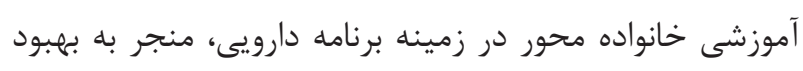

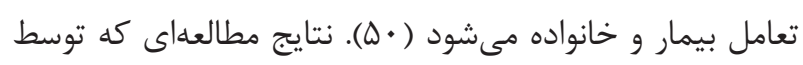

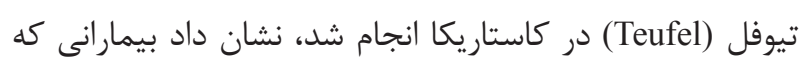

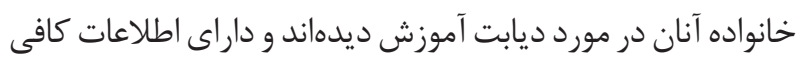
بودهاند و از رفتارهاى بهداشتى توصيه شده حمايت ميى كردند،

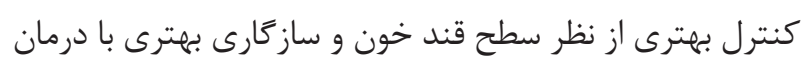

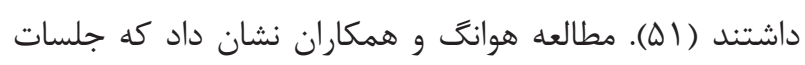

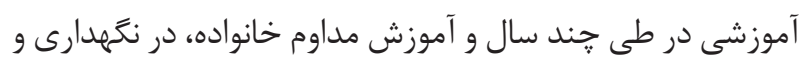

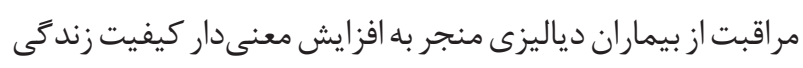

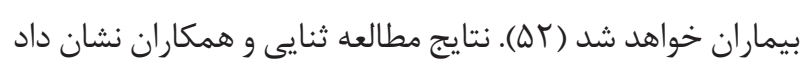

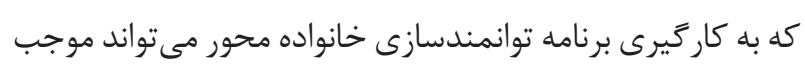

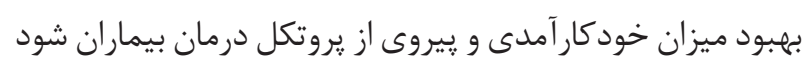

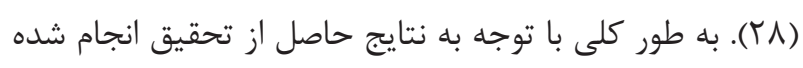

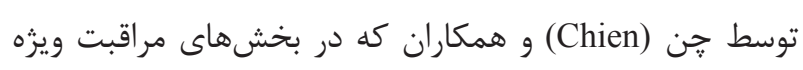

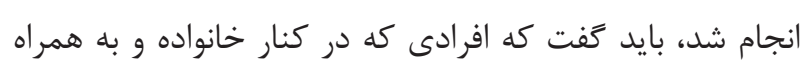

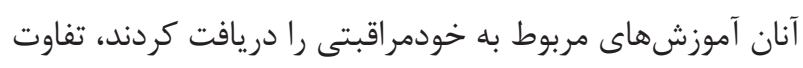

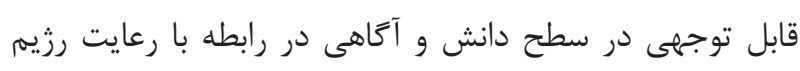

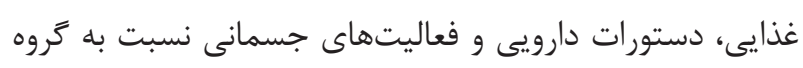
كنترل داشتند (س山). با توجه به نتايج حاصل از يروهش و مقايسه ساير مطالعات مرتبط

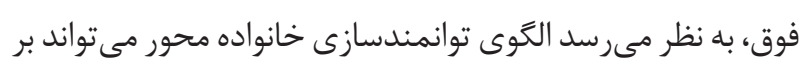

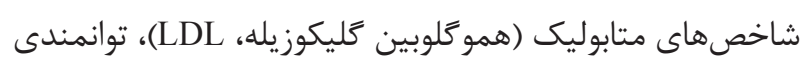

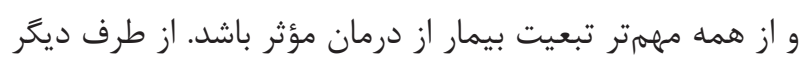

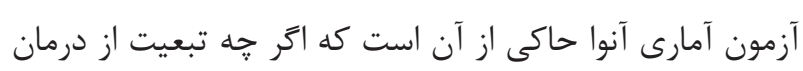

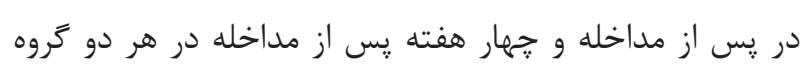

3- Shaw JE, Sicree RA, Zimmet PZ. Global estimates of the prevalence of diabetes for 2010 and 2030. Diabetes Res Clin Pract. 2010;87(1):4-14. DOI: 10.1016/j.diabres.2009.10.007 PMID: 19896746

4- Shirazi M, Anoosheh M, Rajab A. [The effect of self care program education by group discussion method on self concept in diabetic adolescent girls reffered to Iranian Diabetes Society]. Iran J Nurs 
Res. 2011;6(22):40-50.

5- Sabaté E. Adherence to long-term therapies: evidence for action. Geneva, Switzerland: World Health Organization; 2003.

6- Association AD. Diagnosis and classification of diabetes mellitus. Diabetes Care. 2014;37(1):62-9.

7- Delamater AM. Improving Patient Adherence. Clin Diabetes. 2006;24(2):71-7. DOI: 10.2337/diaclin.24.2.71

8- Smeltzer S, Bare B, Hinkle J, Cheever K. Brunner \& Suddarth's Textbook of Medical Surgical Nursing 11th Edition. 11th ed: Wolters Kluwer: Lippincott Williams and Wilkins; 2007.

9- Association AD. Standards of medical care for patients with diabetes mellitus. Diabetes Care. 2011;20(1):5-13.

10- Padala PR, Desouza CV, Almeida S, Shivaswamy V, Ariyarathna $\mathrm{K}$, Rouse L, et al. The impact of apathy on glycemic control in diabetes: a cross-sectional study. Diabetes Res Clin Pract. 2008;79(1):37-41. DOI: 10.1016/j.diabres.2007.06.012 PMID: 17681395

11- Harvey JN, Lawson VL. The importance of health belief models in determining self-care behaviour in diabetes. Diabet Med. 2009;26(1):5-13. DOI: 10.1111/j.1464-5491.2008.02628.x PMID: 19125754

12- Jafarian N, Heydari A. [ the role of health beliefs in the adoption insulin in diabetic patients attending the diabetes research center of Hamadan]. Sci J Hamadan Univ Med Sci. 2000;7(4):54-9.

13- Hamadzadeh S, al e. [Coping styles and self- care behaviors among diabetes patients]. Iran J Nurs 2013;25(80):24-33.

14- Keogh C, al e. Changing illness perception in patient with poorly controlled type 2diabetes a RCT of a family- based interventionprotocol and pilot studey. Biomed Centeral Fam Pract. 2000;8(36):1-100.

15- Helgeson VS, Reynolds KA, Siminerio L, Escobar O, Becker D. Parent and adolescent distribution of responsibility for diabetes self-care: links to health outcomes. J Pediatr Psychol. 2008;33(5):497-508. DOI: 10.1093/jpepsy/jsm081 PMID: 17848390

16- Kooshyar H, Shoorvazi M, Dalir Z, Hosseini M. [Health literacy and its relationship with medical adherence and healthrelated quality of life in diabetic community-residing elderly]. J Mazandaran Univ Med Sci. 2014;24(1):134-43.

17- Tolouei M, al e. [Motivational factors of nurses in the education of patients]. Hayat. 2006;12(2):43-51.

18- Ellis SE, Speroff T, Dittus RS, Brown A, Pichert JW, Elasy TA. Diabetes patient education: a meta-analysis and meta-regression. Patient Educ Couns. 2004;52(1):97-105. DOI: 10.1016/s07383991(03)00016-8 PMID: 14729296

19- Funnell MM, Anderson RM, Arnold MS, Barr PA, Donnelly M, Johnson PD, et al. Empowerment: an idea whose time has come in diabetes education. Diabetes Educ. 1991;17(1):37-41. DOI: 10.1177/014572179101700108 PMID: 1986902

20- Funnell MM, Anderson RM. Empowerment and Self-Management of Diabetes. Clin Diabetes. 2004;22(3):123-7. DOI: 10.2337/ diaclin.22.3.123
21- Alhani F. [Designing and evaluation of family centered empowerment model in preventing iron deficiency anemia ]. Tehran: Tarbiat Modares University; 2003.

22- Park M, Chesla CK. Understanding complexity of Asian American family care practices. Arch Psychiatr Nurs. 2010;24(3):189-201. DOI: 10.1016/j.apnu.2009.06.005 PMID: 20488345

23- Donovan F, Sands K, Judith N, Marianne M, Green C. Phipps medical surgical nursing health and illness perspective 8 th ed. St Louis: Lippincott Williams \& Wilkins; 2007. 882 p.

24- Musick K, Mare RD. Family structure, intergenerational mobility, and the reproduction of poverty: evidence for increasing polarization? Demography. 2004;41(4):629-48. DOI: 10.1016/j. ssresearch.2004.11.006 PMID: 15622947

25- Allahyari A. [The effect of family- centered empowerment model on the Quality of life of school age B- thalassemic children]. Tehran, Iran: Tarbiat Modares Univercity; 2006.

26- Masoodi R, Alhani F, Moghadassi J, Ghorbani M. [The effect of family-centered empowerment model on skill, attitude, and knowledge of multiple sclerosis caregivers]. J Birjand Univ Med Sci. 2010;9:175-82.

27- Vahedian Azimi A, Alhani F, Ahmadi F, Kazemnejad A. [Effect of family-centered empowerment model on the life style of myocardial infarction patients]. Iran J Crit Care Nurs. 2010;2(4):12.

28- Sanaie N, Nejati S, Zolfaghari M, Alhani F, Kazemnezhad A. [The effects of family-based empowerment on family cooperation in following patient treatment regime after coroner arteries bypass surgery]. Mod Care Sci Q Birjand Nurs Midwifery Fac. 2014;11(1):19-27.

29- Hajizadeh E, Asghari M. Looking research methods and statistical analysis. Tehran: Jahad university press; 2011.

30- Salsali M, Silverstone PH. Low self-esteem and psychiatric patients: Part II - The relationship between self-esteem and demographic factors and psychosocial stressors in psychiatric patients. Ann Gen Hosp Psychiatry. 2003;2(1):3. PMID: 12622872

31- Modanloo M. [Development and psychometric tools adherence of treatment in patients with chronic]. Iran: Iran university; 2013.

32- Aghamolaei T, Eftkhar H, Mohammad K, Nakhjavani M, Shojaiezadeh D, Ghofranipour F, et al. [effect of health education program on behavior and health- related quality of life in diabetic patients]. Acta Med Iranica. 2005;43(2):89-94.

33- Mosnier-Pudar H, Hochberg G, Eschwege E, Virally ML, Halimi $\mathrm{S}$, Guillausseau PJ, et al. How do patients with type 2 diabetes perceive their disease? Insights from the French DIABASIS survey. Diabetes Metab. 2009;35(3):220-7. DOI: 10.1016/j. diabet.2009.02.001 PMID: 19303338

34- Milenkoviæ T, Gavriloviæ S, Percan V, Petrovski G. Influence of diabetic education on patient well-being and metabolic control. Diabetologia Croat. 2004;33(3):91-6.

35- Sadeghi M, Pedram Razi S, Nikbakht Nasrabadi A, Ebrahimi H, Kazemnejad A. [Comparison of the impact of education based on the empowerrment model and family-center empowerrment 
model on knowledge and metabolic control of patients with type 2 diabetes mellitus]. J Nurs Educ. 2013;2(3):18-27.

36- Heydari M, Mir Mohammad Ali M, Khakbazan Z, Mahmoodi M. [The study of comparison of two educational methods of lecture and training package on self-efficacy 9-12 years old girls student in relation with adolescent health]. Iranian J Nurs Res. 2015;1(36):1-15.

37- Alizadeh H, Nasirifard N, Karami A. [The effect of training on the efficacy of Adlerian-based encouragement of self-esteem in adolescent girls. Winter 2010]. Soc Stud Psychol Women. 2010;4(26):143-67.

38- Heidari M, Alhani F, Kazemnejad A, Moezzi F. [The effect of empowerment model on quality of life of diabetic adolescents]. Iran J Pediatr. 2007;17(1):87-94.

39- Hakim A, Mahmoodi F, Alijani Renani H, Latifi M. [Effect of family-centered empowerment model on treatment regimen of the school-aged children with diabetes: A randomized controlled trial]. Jundishapur J Chron Dis Care. 2013;2(2):46-53.

40- Samadi N, Safavi M, Mahmoodi M. [The relationship between quality of life and self-esteem in patient with type 2 diabetes in Ardabil 2011. A short report]. Rafsanjan J Med Sci. 2011;12(3):251-6.

41- Armour TA, Norris SL, Jack L, Jr., Zhang X, Fisher L. The effectiveness of family interventions in people with diabetes mellitus: a systematic review. Diabet Med. 2005;22(10):1295-305. DOI: 10.1111/j.1464-5491.2005.01618.x PMID: 16176186

42- Lustman PJ, Anderson RJ, Freedland KE, de Groot M, Carney RM, Clouse RE. Depression and poor glycemic control: a metaanalytic review of the literature. Diabetes Care. 2000;23(7):93442. PMID: 10895843

43- Wong FK, Mok MP, Chan T, Tsang MW. Nurse follow-up of patients with diabetes: randomized controlled trial. J Adv Nurs. 2005;50(4):391-402. DOI: 10.1111/j.1365-2648.2005.03404.x PMID: 15842446

44- Kim HS, Kim NC, Ahn SH. Impact of a nurse short message service intervention for patients with diabetes. J Nurs Care Qual. 2006;21(3):266-71. PMID: 16816608

45- Ghavami H, Ahmadi F, Entezami H, Memarian R. [Effect of applying continuous care model on quality of life in diabetic patients]. Tehran, Iran: Tarbiat Modares Univercity; 2004.

46- Rakhshandehru S, Heydarnia A, Rajab A. [Effect of education on quality of life of diabetic patients]. Shahed J Med. 2002;62:15-20.

47- Narges G, Maddah Sadat SB, Dalvandi A, Arsalani N, Farzi M. The effect of education of self care behaviors based on family-centered empowerment model in type II diabetes. J Sch Nurs Midwifery Shahid Beheshti Univ Med Sci Health Serv. 2014;23(83):43-50.

48- Razmaraei S, Hemmati Maslakpak M, Khalkhali H. [The Effect Of Family-Centered Education On Self-Care In Patients With Type 2 Diabetes]. J Urmia Nurs Midwifery Fac. 2016;14(2):118-27.

49- Aggarwal B, Liao M, Allegrante JP, Mosca L. Low social support level is associated with non-adherence to diet at 1 year in the Family Intervention Trial for Heart Health (FIT Heart). J Nutr Educ Behav. 2010;42(6):380-8. DOI: 10.1016/j.jneb.2009.08.006 PMID: 20696617

50- Gance-Cleveland B. Motivational interviewing: improving patient education. J Pediatr Health Care. 2007;21(2):81-8. DOI: 10.1016/j. pedhc.2006.05.002 PMID: 17321907

51- Teufel-Shone NI, Drummond R, Rawiel U. Developing and adapting a family-based diabetes program at the U.S.-Mexico border. Prev Chronic Dis. 2005;2(1):A20. PMID: 15670473

52- Kwon HS, Cho JH, Kim HS, Lee JH, Song BR, Oh JA, et al. Development of web-based diabetic patient management system using short message service (SMS). Diabetes Res Clin Pract. 2004;66 Suppl 1:S133-7. DOI: 10.1016/j.diabres.2003.10.028 PMID: 15563964

53- Chien WT, Chiu YL, Lam LW, Ip WY. Effects of a needs-based education programme for family carers with a relative in an intensive care unit: a quasi-experimental study. Int J Nurs Stud. 2006;43(1):39-50. DOI: 10.1016/j.ijnurstu.2005.01.006 PMID: 16183062

54- Hashemi S, Tayebi A, Rahimi A, Einolahi B. [Examining the effect of continuous care model on adherence to dietary regimen among patients receiving hemodialysis]. J Crit Care Nurs. 2015;7(4):21520.

55- Musavifar A, Zolfaghari M, Pedram S, Haghani H. [Assess follow-up (mobile, phone) on adherence to treatment in patient with diabetes]. Iran Diabetes Lipid J. 2012;10(4):407-18. 


\title{
The Effectiveness of "Family-Centered Empowerment Model" on the Treatment Adherence of Patients with Type II Diabetes and Heart Disorder Admitted to AJA Hospitals, During Year 2015
}

\author{
Rezai Asl. $\mathrm{H}^{1}$, *Seyyed Mazhari. $\mathrm{M}^{2}$, Pishgooi. SAH${ }^{3}$, Alhani. $\mathrm{F}^{4}$
}

\begin{abstract}
Introduction: Training of patients with diabetes and heart disease is a major problem in achieving optimal adherence to the treatment regimen. One of the most influential factors is selecting an appropriate teaching method. On the other hand, focusing on proper education for the patients> family could facilitate the desired management and better control of the disease.
\end{abstract}

Objective: The aim of this study was to investigate the effect of the family-centered empowerment model on treatment adherence in patients with type II diabetes and heart problems.

Materials and Methods: This study was a clinical trial, in which 62 patients with type II diabetes and heart disorders were selected from AJA hospitals, during year 2015. In order to collect data, a demographic questionnaire, treatment adherence in chronic diseases questionnaire, and empowerment questionnaire, with parameters HBA1C and LDL were used. All questionnaires were handed over and filled in by 2 groups, before and after the intervention; the treatment adherence in chronic diseases questionnaire was handed over and filled in 4 weeks after the intervention. The data was analyzed using the SPSS version 21 software and chi-square test, Fishers exact test, independent sample $\mathrm{t}$ test, paired sample $t$ test, and repeated measures analysis (ANOVA).

Results: No significant differences was found in demographic factors between the two groups before the intervention $(\mathrm{P}>0.05)$. There was no statistically significant difference in the mean scores of empowerment of patients and family members, knowledge, treatment adherence in chronic diseases, and the mean value of HBA1C and LDL before the intervention ( $\mathrm{P}>0.05)$, yet after the interventions, a statistically significant difference was observed between the variables $(\mathrm{P}<0.05)$, except the variable LDL, for which the difference was not statistically significant $(\mathrm{P}>0.09)$. The coefficient of variation showed that the reduction of LDL was greater in the intervention group than the control group.

Discussion and Conclusion: The findings showed the positive effects of the implementation of family-centered empowerment model to increase treatment adherence in the patients. Given the important role of the family in the management and control of chronic diseases, including type 2 diabetes and it's complications, especially heart disease, using this template to achieve biologically optimal adherence is recommended.

Keywords: Educational, Family-Centered Empowerment Model, Heart Disorders, Type 2 Diabetes.

Rezai Asl H, Seyyed Mazhari M, Pishgooi A, Alhani F. The Effectiveness of «Family-Centered Empowerment Model» on the Treatment Adherence of Patients with Type II Diabetes and Heart Disorder Admitted to AJA Hospitals, During Year 2015. Military Caring Sciences. 2017; 4 (1). 58-69.

Submission: 4/2/2017

Accepted: 6/3/2017

Published: 17/6/2017

1- MSc in Student of Critical Care Nursing, Iran, Tehran, AJA University Of Medical Science, Faculty of Nursing.

2- (*Corresponding Author) MSc in Nursing, Instructor, Iran, Tehran, AJA University of Medical Science, Faculty of Nursing, Medical-Surgical Department. Email: Marjanmazhari@yahoo.com

3- Ph.D. in Nursing Education, Assistant Professor, Iran, Tehran, AJA University Of Medical Science, Faculty of Nursing, Medical-Surgical Department. 4- Ph.D. in Nursing Education, Associate Professor, Iran, Tehran, Tarbiat Modares University, Faculty of Medicine, Nursing Department. 